\title{
Socio-economic Importance of Biomaterials in the Transition to the Circular Economy Model
}

\author{
Magdalena Wojnarowska ${ }^{1, *}$, Mariusz Sołtysik ${ }^{2}$, and Maciej Guzik ${ }^{3}$ \\ ${ }^{1}$ Cracow University of Economics, College of Management Sciences and Quality, Department of \\ Technology and Ecology of Products, ul. Rakowicka 27, 31-510 Krakow, Poland \\ ${ }^{2}$ Cracow University of Economics, College of Management Sciences and Quality, Management \\ Process Department, ul. Rakowicka 27, 31-510 Krakow, Poland \\ ${ }^{3}$ Jerzy Haber Institute of Catalysis and Surface Chemistry Polish Academy of Sciences, \\ Niezapominajek 8, 30-239 Krakow, Poland
}

\begin{abstract}
.
Research background: The adoption of the 2030 Agenda for Sustainable Development obliges individual countries to take actions aimed at achieving the seventeen goals of sustainable development. One of the tasks is to transform the economy into a circular economy. The necessity of transformation results from the growing number of manufactured products and the growing amount of generated waste, especially those made of plastics. Waste management and disposal may also have significant environmental effects. Therefore, EU waste management policy aims to reduce the impact of waste on the environment and health and to improve the efficient use of resources in the EU. The long-term goal of this policy is to reduce the amount of waste generated, and if its generation is unavoidable, to promote its use as resources, to increase recycling and to ensure safe disposal of waste. Hence the need to change the current economic model based on a linear approach to the circular economy. The technological goal of the circular economy is to achieve the highest possible level of waste recovery and recycling, and then reuse it in production. A possible alternative to conventional and petroleum-based materials are biopolymers that are biodegradable in the natural environment, and their degradation products do not endanger human and animal health. Thanks to these properties they not only can replace traditional polymers, but also will find completely new applications in biomedical engineering and medicine.

Purpose of the article: The aim of the article is to analyze the socioeconomic consequences of using biomaterials in the transition to the $\mathrm{GOZ}$ model.

Methods: A systematic literature review methodology.

Findings \& Value added: The main findings relate to the socio-economic consequences of introducing biomaterials for both consumers and businesses.
\end{abstract}

Keywords: circular economy; biomaterials; business models

*Corresponding author: wojnarom@uek.krakow.pl 
JEL Classification: $D 40 ; D 47 ; O 30$

\section{Introduction}

Economic activity, especially production, is based on the use of natural resources, therefore the relationship between the enterprise and the environment implies expectations in terms of limiting the negative impact of the enterprise on the environment. The global recession, uncertain competitive environment, the need to reduce costs, etc. force enterprises to implement alternative solutions, including environmental ones. Faced with the emerging difficulties, sustainable development and the circular economy have become two important issues for the future and the competitiveness of enterprises. The programs for integrating sustainable development with industrial activities include both changes to production processes to reduce their impact on the environment, the development of new green products and the redesign of the business model.

The adoption of the 2030 Agenda for Sustainable Development obliges individual countries to take actions aimed at achieving the seventeen goals of sustainable development. One of the tasks is to transform the economy into a circular economy (Schroeder et al., 2019). The necessity of transformation results from the growing number of manufactured products and the growing amount of generated waste, especially those made of plastics. Waste management and disposal may also have significant environmental effects. Therefore, EU waste management policy aims to reduce the impact of waste on the environment and health and to improve the efficient use of resources in the EU. The longterm goal of this policy is to reduce the amount of waste generated, and if its generation is unavoidable, to promote its use as resources, to increase recycling and to ensure safe disposal of waste (Amasuomo \& Baird, 2016). Hence the need to change the current economic model based on a linear approach to the circular economy. The technological goal of the circular economy is to achieve the highest possible level of waste recovery and recycling, and then reuse it in production. A possible alternative to conventional and petroleum-based materials are biopolymers that are biodegradable in the natural environment, and their degradation products do not endanger human and animal health. Thanks to their properties such as biodegradability and biocompatibility, they can not only replace traditional polymers, but also find completely new applications in biomedical engineering and medicine.

The circular economy model is a relatively new and constantly developing area for many researchers, which is the opposite of the currently functioning linear economy (based on the four principles: take, create, consume and discard) (Bonciu, 2014). The technological goal of the circular economy is to achieve the highest possible level of recovery and recycling of waste, and then its reuse in production. A possible alternative to conventional and petroleum-derived materials are biopolymers, which are biodegradable in the natural environment and their degradation products do not pose a threat to human and animal health. Thanks to their properties, such as biodegradability and biocompatibility, they can not only replace traditional polymers, but also find completely new applications in biomedical engineering and medicine. The use of such an approach allows achieving both social, economic and environmental benefits.

The purpose of the chapter is to analyze the socio-economic consequences of the use of biomaterials in the transition to the circular economy model. The main findings concern the socio-economic consequences of the introduction of biomaterials for both consumers and businesses.

The article reviews the literature in the context of:

- Circular economy,

- Analyzes of traditional polymers 
- Application possibilities of biopolymers.

\section{Methodology}

\subsection{Definition of the concept Circular Economy}

The concept of a circular economy first appeared in the literature in the late 1970s. It was during this period that a certain relationship between the economy and natural resources was first noticed. In 2002, Braungart and William McDonough published a book called Cradle to Cradle: Remaking the Way We Make Things, a manifesto for cradle-to-cradle design that gives specific details of how to achieve the model. The definition proposed by Michael Braungart and Willian McDonough underpins their cradle to cradle philosophy, which assumes that producers, by observing the natural environment, take actions aimed at eliminating or minimizing the amount of generated waste (McDonough \& Braungart, 2007). According to this concept, the manufacturer should assume full responsibility for the manufactured product.

The main task of the circular economy is to reduce the amount of generated waste or eliminate it completely by applying preventive measures (Geissdoerfer et al., 2017). As part of the closing of the loop, two types of cycles can be distinguished: biological and technical. The biological cycle is related to the stream of biodegradable materials, while the technical cycle relates to the management of non-renewable resources, their reuse and recovery. The two circuits differ in the driving factor of reuse and reuse of resources into the circuits. In the biological cycle, it occurs naturally as a result of biological processes, while in the case of technical circulation, the cute print is man (D'Amato et al., 2017). The butterfly model indicates the 3 most important principles of the circular economy, which include (Ellen MacArthur Foundation, 2012):

- maintenance and expansion of natural resources as a result of their control and the sustainability of alternative resources,

- optimization of resource consumption as a result of stopping the circulation (biological and technical cycle) of materials, products and components, while maintaining their highest usability,

- perfecting the system for better performance by identifying and eliminating negative externalities.

The idea of a circular economy should be taken into account at all stages of the product life cycle, from the process of product design to their disposal.

\subsection{Waste management}

It should be emphasized that the waste defined in the Journal 2019 item 701 in Chapter 2 of Art. 3 clause 1 2018/851 as "any substance or object which the holder discards or intends or is required to discard" potentially means a waste of resources in the form of materials and energy. Waste management and disposal can also have serious environmental effects. Therefore, EU waste management policy aims to reduce the environmental and health impacts of waste and to improve resource efficiency in the EU. The long-term goal of this policy is to reduce the amount of waste generated and, if its generation is inevitable, to promote its use as a resource, to make recycling more widely and to ensure safe disposal of waste.

Unfortunately, despite the adopted goals, the production, recycling and incineration of plastic elements each year emit about 400 million tons of $\mathrm{CO}_{2}$, and the global scenario assuming maintaining the dynamics of growth for plastics assumes that by 2050. this 
pollution could rise to 12,000 million tonnes (Ivar Do Sul \& Costa, 2014). The presented data do not take into account the growing plastic waste from the pandemic period, i.e. waste in the form of e.g. disposable gloves, masks, etc. Enterprises wanting to meet the demand produce an increasing number of products, which is associated with the need to provide raw materials, materials, energy, water, fuels and other components necessary to produce goods.

The accumulation of huge amounts of plastic waste in landfills and the lack of biodegradability is a fundamental environmental problem (Tokiwa et al., 2009). Estimates show that by 2015 as much as 6,300 million tonnes of plastics were produced, of which only $9 \%$ was recycled and $12 \%$ was incinerated for energy. The remaining $79 \%$ has ended up in landfills or is deposited in the environment (Geyer et al., 2017). Estimated studies indicate that every year, about 1-2 million tons of plastic waste ends up in the oceans which, when exposed to sunlight and sea waves, degrades into particles smaller than $5 \mathrm{~mm}$. Over time, the resulting polymer particles become a link in food chains, thus getting into food products. The presence of these particles jeopardizes human health and safety due to e.g. the ability to penetrate the lung surface by polymer microparticles $<10 \mu \mathrm{m}$ (Lebreton et al., 2017).

With the current consumption rates, it is estimated that by 2050 polymer production will reach 33 billion tonnes. A significant problem related to the use of plastics is their low biodegradability (Tokiwa et al., 2009), and even for most synthetic polymers, the complete absence of these processes. The non-biodegradable polymers include e.g. polyethene (PE), polypropylene (PP), polyethene terephthalate (PET), polyurethanes (PUR) and polyamides (PA). On the other hand, biodegradable synthetic polymers include poly (glycolic acid) (PGA) and polycaprolactone (PCL) (Shastri, 2005). Traditional plastics are resistant to external conditions and have never been shown to be biodegradable under natural conditions or in industrial compost. The multi-million production scale and the widespread use of plastics in combination with their landfilling and non-recovery have led to serious waste management problems. For example, in 2014, almost a fifth of the more than 180 million tonnes of waste generated in the US was plastics (The Statistics Portal - Statista, 2016).

Until now, traditional plastics have been used in many different products and have displaced other materials such as wood, metal or glass. They can be formed into materials for use in fabrics and textiles, food packaging, eyeglasses, compact discs, and more. Durability and low production costs made plastic almost indispensable materials in modern society. The growing demand for cheap and durable plastics is leading to the rapidly growing global problem of clinging waste in the environment. Many different technologies are still being developed to tackle the problem of plastic waste. However, these recycling technologies mainly focus on energy recovery or mechanical treatment (Association of Plastics manifacturors, 2018).

While the waste management situation in Europe is improving, landfilling is still the first or second most common form of treatment of plastic waste in many countries. In countries such as Switzerland, Austria and Germany, virtually no plastic waste is disposed of in landfills. More than $70 \%$ of plastic waste is processed in these countries through energy recovery, the rest is recycled. However, the new EU Member States, along with Poland, Spain and Greece, are lagging behind these trends as less than $40 \%$ of plastic waste is recovered. The difference in recovery and recycling rates between European countries is significant. Existing regulations are of great importance for waste management in individual countries. Some countries have specific regulations (Switzerland, Austria, Germany, Netherlands), while others have plastic producers trying to meet recycling targets on a voluntary basis (UK, Belgium, France). In the worst case, there are countries where no laws or restrictions have been implemented (Bulgaria, Lithuania, Romania). The state of 
legislation in a given region clearly translates into the amount of plastic that can be found in landfills and that are not recycled in any way (Plastics - the Facts 2017).

\section{Results}

A possible alternative to conventional and petroleum-based materials are polymers that biodegrade in the natural environment and their degradation products do not endanger human and animal health. Thanks to their properties, such as biodegradability and biocompatibility, they can not only replace traditional polymers but also find completely new applications in biomedical engineering and medicine. Thanks to the completely natural character, bacteria-derived polyhydroxyalkanoates (PHA) (Możejko-Ciesielska \& Kiewisz, 2016) belonging to the group of aliphatic polyesters, are fully biodegradable. They can be produced from virtually any carbon source including renewable raw materials. They seem to emerge as a group of a promising alternative to traditional polymers produced from crude oil. They also meet the expectations set by today's industry, medicine and are in line with global trends in environmental protection and reduction of greenhouse gas emissions. Thanks to the above, they fit perfectly into role of replacement in two categories: medical and non-medical areas.

Current research and trends indicate that biopolymers can be used in the production of widely understood everyday objects, such as packaging, personal protective equipment, housings for electronic devices or even furniture and household to their chemical structure, both PHA and PLA can be easily appliances (Chen, 2009). Due modified, thus controlling their biological, chemical and physical properties, such as hydrophobicity, Young's modulus or hardness (Witko et al., 2018). These features make it possible to produce universal polymers that can have features tailored to the specific needs of the market, and the constraints caused by the properties of the raw material are greatly reduced.

Rapid advances in areas such as immunology and the understanding of the body's response to a foreign body triggered the intensive development of first-generation biomaterials in the 1960s and 1970s. These materials were designed to match the mechanical properties of the replaced tissue and by preventing protein adsorption and cell adhesion. The next stage of development took place in the early 1980s, research focused on substances capable of active interaction with the environment. Second generation biomaterials have been designed to be "bioactive" by inducing specific and expected cellular responses such as cell adhesion, proliferation and differentiation to a specific cell type (Witko et al., 2018). An additional advance over the first-generation materials was the concept of biodegradability, which allows for a controlled chemical breakdown of a substance that can thus be directly eliminated from the body. While second-generation biomaterials have been designed to be either resorbable or bioactive, the next generation of biomaterials combines these two properties. Third-generation biomaterials are designed to stimulate specific cellular responses at the molecular level. Third-generation bioactive glasses and macroporous ceramic implants are designed to activate genes that stimulate regeneration of living tissues (Cichon et al., 2019). The cellular and molecular basis of the development of third-generation biomaterials allows the work on scaffolds for tissue regeneration and repair in situ with minimally invasive surgery.

Biopolymers, especially polyhydroxyalkanoates, which are divers in their structure and physicochemical properties, with ease can replace traditional polymers in many areas of human life. Slowly the agenda set by the main political forces across the globe is helping with the transition from traditional to green products, within the circular economy principles. This also impacts the production and use of the biopolymers. The PHA family can easily fit into the global trends, with their manufacturing technologies being adapted to the local needs and possibilities. These factors will also impact the price, which still seems 
to be high and uncompetitive with the traditional ones. In the upcoming years we will be witnessing the global green revolution where PHA-type biobased products will play a crucial role.

\section{Discussion and Conclusion}

The conducted analysis of the literature allows us to conclude that biodegradable biopolymers are an opportunity to replace synthetic polymers, which are currently a suitable alternative, for example due to the possibility of their accumulation both from renewable resources (e.g. starch, cellulose) and inside living organisms. They can also be obtained with the use of biotechnological processes (PHAs), e.g. with the use of natural strains or genetically modified organisms. Despite the numerous advantages resulting from the environmental benefits, a major limitation associated with the production of biopolymers at the moment is the high production costs of these materials (e.g. PHAs). The production costs of this biopolymer are currently about 4 times higher than the production costs of traditional synthetic polymers (Johnston et al., 2018). However, a report prepared by the European Bioplastics and NovaInstitute in 2018 points out that the global production capacity of biopolymers is to increase by $24 \%$ by 2023 (Global Production Capacities of Bioplastics 2018-2023 Bioplastics Market Data 2018, 2018). In order to reduce production costs further of the biopolymers worldwide, there is a need for the search of cheap sources of waste carbon produced locally, which may be for example appropriately converted postproduction and post-consumer wastes.

The Project has been financed by the Ministry of Science and Higher Education within "Regional Initiative of Excellence" Programme for 2019-2022. Project no.: 021/RID/2018/19. Total financing: 11897 131,40 PLN.

\section{References}

1. Amasuomo, E., Baird, J. (2016). The concept of waste and waste management. Journal of Management and Sustainability, 6(4), 88-96.

2. Association of Plastics manifacturors. (2018). Plastics - The facts 2018. Plastics Europe, 71(1-2), 299-306.

3. Bonciu, F. (2014). The European economy: From a linear to a circular economy. Romanian Journal of European Affairs, 14(4), 78-91.

4. Chen, J. Z. (2009). Material flow and circular economy. Systems Research and Behavioral Science, 26(2), 269-278.

5. Cichon, E., Harazna, K., Skibinski, S., Witko, T., Zima, A., Slósarczyk, A., Zimowska, M., Witko, M., Leszczynski, B., Wrobel, A., Guzik, M. (2019). Novel bioresorbable tricalcium phosphate/polyhydroxyoctanoate (TCP/PHO) composites as scaffolds for bone tissue engineering applications. Journal of the Mechanical Behavior of Biomedical Materials, 98, 235-245.

6. D’Amato, D., Droste, N., Allen, B., Kettunen, M., Lähtinen, K., Korhonen, J., Leskinen, P., Matthies, B. D., Toppinen, A. (2017). Green, circular, bio economy: A comparative analysis of sustainability avenues. Journal of Cleaner Production, 168, 716-734.

7. Ellen MacArthur Foundation. (2012). Ellen Mcarthur towards a circular economy. Journal of Industrial Ecology, 10(1-2), 4-8.

8. Geissdoerfer, M., Savaget, P., Bocken, N. M. P., Hultink, E. J. (2017). The Circular 
economy - A new sustainability paradigm? Journal of Cleaner Production, 143, 757768 .

9. Geyer, R., Jambeck, J. R., Law, K. L. (2017). Production, use, and fate of all plastics ever made. Science Advances, 3(7), e1700782.

10. Global production capacities of bioplastics 2018-2023 Bioplastics market data 2018. (2018).

11. Ivar Do Sul, J. A., Costa, M. F. (2014). The present and future of microplastic pollution in the marine environment. Environmental Pollution, 185, 352-364.

12. Johnston, B., Radecka, I., Hill, D., Chiellini, E., Ilieva, V. I., Sikorska, W., Musioł, M., Zięba, M., Marek, A. A., Keddie, D., Mendrek, B., Darbar, S., Adamus, G., Kowalczuk, M. (2018). The microbial production of Polyhydroxyalkanoates from Waste polystyrene fragments attained using oxidative degradation. Polymers, 10(9), 957.

13. Lebreton, L. C. M., van der Zwet, J., Damsteeg, J.-W., Slat, B., Andrady, A., Reisser, J. (2017). River plastic emissions to the world's oceans. Nature Communications, $8(1), 15611$.

14. McDonough, W., Braungart, M. (2007). Remaking the way we make things: Creating a new definition of quality with cradle-to-cradle design. The International Handbook on Environmental Technology Management, 33-48.

15. Możejko-Ciesielska, J., Kiewisz, R. (2016). Bacterial polyhydroxyalkanoates: Still fabulous? Microbiological Research, 192, 271-282.

16. Plastics - the Facts 2017. (n.d.).

17. Schroeder, P., Anggraeni, K., Weber, U. (2019). The relevance of circular economy practices to the sustainable development goals. Journal of Industrial Ecology, 23(1), 77-95.

18. Shastri, V. (2005). Non-degradable biocompatible polymers in medicine: Past, present and future. Current Pharmaceutical Biotechnology, 4(5), 331-337.

19. The Statistics Portal - Statista. (2016).

20. Tokiwa, Y., Calabia, B. P., Ugwu, C. U., Aiba, S. (2009). Biodegradability of plastics. International Journal of Molecular Sciences, 10(9), 3722-3742.

21. Wang, B., Sharma-Shivappa, R. R., Olson, J. W., Khan, S. A. (2013). Production of polyhydroxybutyrate (PHB) by Alcaligenes latus using sugarbeet juice. Industrial Crops and Products, 43(1), 802-811.

22. Witko, T., Guzik, M., Sofińska, K., Stepien, K., Podobinska, K. (2018). Novel biocompatible polymers for biomedical applications. Biophysical Journal, 114(3), 363a. 